\title{
$Q$ fever: a new ocular manifestation
}

This article was published in the following Dove Press journal:

Clinical Ophthalmology

5 September 201 I

Number of times this article has been viewed

\author{
P Udaondo ${ }^{1,3}$ \\ S Garcia-Delpech ${ }^{1,2}$ \\ D Salom ${ }^{1,2}$ \\ M Garcia-Pous' \\ M Diaz-Llopis ${ }^{1,2}$ \\ 'Department of Ophthalmology, \\ Nuevo Hospital Universitario y \\ Politecnico La Fe, Valencia, Spain; \\ ${ }^{2}$ Faculty of Medicine, Universitat de \\ València, Valencia, Spain; ${ }^{3}$ Universidad \\ Cardenal Herrera CEU, Valencia, \\ Spain
}

Correspondence: Patricia Udaondo Department of Ophthalmology, Nuevo Hospital Universitario y Politecnico La Fe, Universitario Calle Botánico 7, Pta I4, 46008 Valencia, Spain

Tel +346 47869228

Email patyudaondo@hotmail.com
Abstract: Q Fever is a zoonosis caused by Coxiella burnetii. Ocular manifestations are rare in this infection. We describe the case of a man complaining of an intense retro-orbital headache, fever, arthralgia, and bilateral loss of vision, who showed an anterior uveitis accompanied by exudative bilateral inferior retinal detachment and optic disk edema. At the beginning, a Vogt-Koyanagi-Harada (VKH) syndrome was suspected, but the patient was diagnosed with Q fever and treatment with doxycycline was initiated, with complete resolution after 2 weeks. We wondered if Q fever could unleash VKH syndrome or simulate a VKH syndrome by a similar immunological process.

Keywords: Q fever, Vogt-Koyanagi-Harada syndrome, panuveitis, exudative retinal detachment

\section{Introduction}

Q fever is a zoonosis caused by infection with Coxiella burnetii (Rickettsia burnetti), a strictly intracellular organism. Unlike other rickettsiae, which are transmitted to humans by the bite of contaminated arthropods, ${ }^{1}$ C. burnetii is generally transmitted through inhalation of infected aerosols. Clinical polymorphism, ranging from nonspecific to severe syndromes, is characteristic of $\mathrm{Q}$ fever, although its clinical features are often vague and self-limiting. C. burnetii infections can be either acute or chronic. Because of the range of manifestations occurring in acute cases, diagnosis is very difficult. Chronic Q fever almost always involves endocarditis, but hepatitis, osteomyelitis, and endovascular infection have also been described. Early diagnosis is important because the prognosis may depend on when the correct treatment is initiated. ${ }^{1,2}$

A great number of ocular alterations occur in the course of other rickettsiae but not $C$. burnetti, with the most important related to $R$. conorii infection, ie, keratitis, panuveitis, or serous retinal detachment. ${ }^{3-5}$ Only a few cases of ocular manifestations caused by $C$. burnetii appear in the literature, with optic nerve involvement being most common. ${ }^{6,7}$

\section{Case report}

A 33-year-old man complained of intense retro-orbital headache, fever, arthralgia, and bilateral loss of vision of 15 days' duration. Visual acuity in both eyes was counting fingers. The first sign we encountered in the examination was a horizontal nystagmus. Anterior segment biomicroscopy showed a nongranulomatous uveitis, and dilated funduscopic examination revealed an exudative bilateral inferior retinal detachment and optic disk edema (Figures 1 and 2). Further analyses included a brain scan, lumbar puncture, and complete laboratory and serologic tests. 


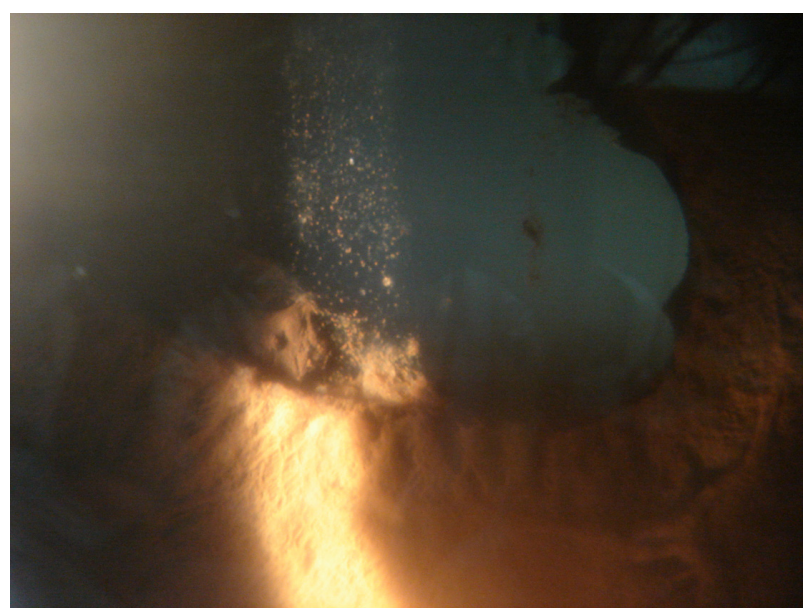

Figure I Details of anterior uveitis in our patient.

Vogt-Koyanagi-Harada (VKH) syndrome was suspected, so corticosteroid treatment was initiated. Ten days later, the patient had not improved. Ocular and neurological manifestations were the same as at initial presentation. The situation worsened when the patient presented in acute renal failure with high creatinine and urea, and proteinuria and hematuria. All results were negative except for unexpected positive IgM (1/64) and IgG (1/264) titers for C. burnetti (phase II antigen), leukocytosis $\left(17.3 \times 10^{9} / \mathrm{L}\right)$, and deranged liver enzymes. Indirect immunofluorescent antibody tests were repeated and confirmed the diagnosis (IgG reached titers of 1/1024).

At this point, we changed our treatment strategy and the patient was treated with doxycycline $100 \mathrm{mg}$ every 12 hours for 3 weeks. Two weeks later, visual acuity was 20/20, the

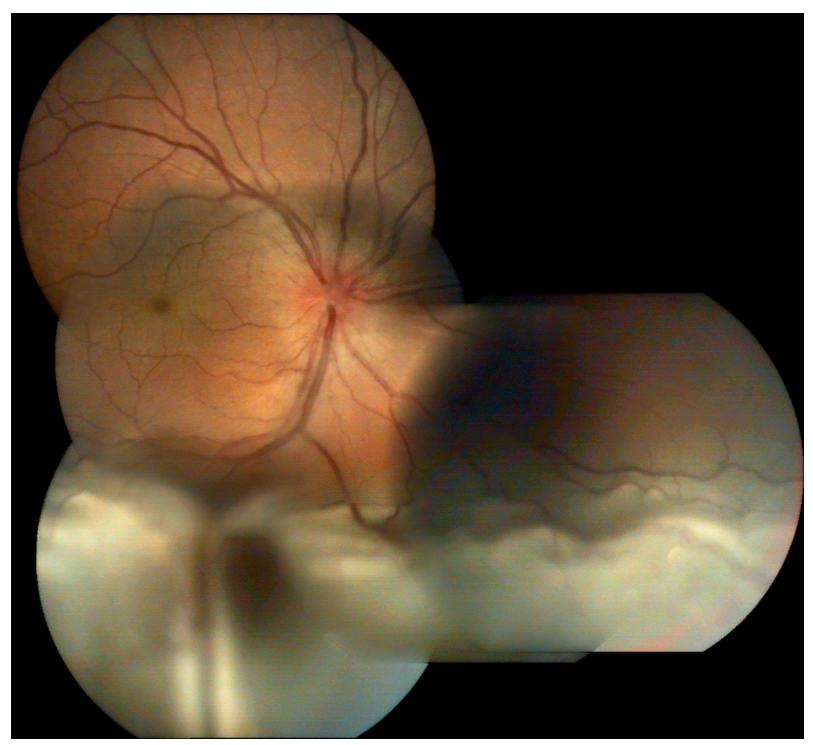

Figure 2 Exudative inferior retinal detachment and disk edema in the right eye, same as in the left eye. retinal detachment had resolved in both eyes (Figure 3), neurological symptoms had disappeared, and renal failure resolved successfully.

\section{Discussion}

VKH syndrome consists of ocular inflammation that involves extraocular organs, so it may be associated with neurological, auditory, and cutaneous manifestations. Different studies indicate that VKH disease is a probable response to an aberrant cell-mediated autoimmune reaction against melanocytes. ${ }^{8}$ This syndrome has been reported to occur in association with other autoimmune disorders and viral infection by way of a trigger for $\mathrm{VKH}$ or concomitant procedures.

In our case, VKH could only explain some of the manifestations, such as ocular signs or hair loss, but not the renal failure and hepatitis. On the other hand, ocular alterations have rarely been described in $\mathrm{Q}$ fever, with optic neuritis and abducens paralysis being the most common pathology in the literature. However, there are no reports of exudative retinal detachment. Our patient had confirmed Q fever with neurological, hepatic, and renal manifestations. Renal involvement in acute C. burnetii is rare. ${ }^{9}$ Our investigations excluded other infective and noninfective causes of acute renal failure, and the patient's condition resolved with appropriate antimicrobial therapy.

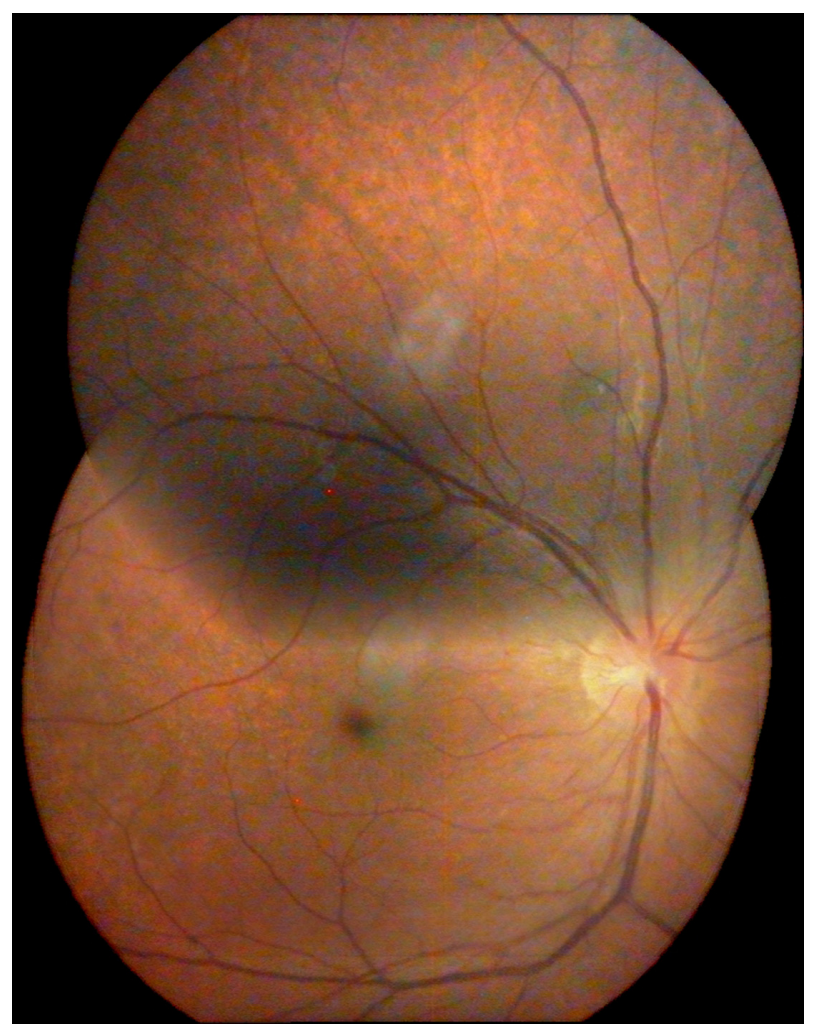

Figure 3 Appearance of the retina 3 weeks after treatment was commenced. Both the retinal detachment and disk edema have resolved. 
The mechanism by which C. burnetii infection may cause symptoms is not well understood. There have been numerous reports of granulomatous changes in liver and bone marrow samples obtained from infected patients. ${ }^{10}$ Large amounts of activated $\mathrm{T}$ lymphocytes have been found in bronchial lavage from patients with necrotizing bronchitis associated with chronic Q fever, ${ }^{11}$ and circulating immune complexes have been detected in acute $\mathrm{Q}$ fever. ${ }^{12} \mathrm{Clinical}$, histological, and immunological findings suggest that $Q$ fever may induce remarkable changes in the immune system comparable with autoimmunoreactive disease.

In conclusion, we wonder whether $\mathrm{Q}$ fever could unleash VKH syndrome or simulate a VKH syndrome via a similar immunological process, and we recommend thinking about C. burnetii when a patient presents with severe ocular symptoms. Prompt diagnosis is important to avoid ocular sequelae.

\section{Disclosure}

The authors report no conflicts of interest in this work.

\section{References}

1. Fariñas MT, Collado CM. Infection by Coxiella burnetti (Q fever). Enferm Infecc Microbiol Clin. 2010;28(Suppl 1):29-32.

2. Gikas A, Kokkini S, Tsioutis C. Q Fever: clinical manifestations and treatment. Expert Rev Anti Infect Ther. 2010;8:529-539.
3. Khairallah M, Ladjimi A, Chakroun M, et al. Posterior segment manifestations of Rickettsia conorii infection. Ophthalmology. 2004;111: 529-534.

4. Alio J, Ruiz-Beltran R, Herrera I, Artola A, Ruiz-Moreno JM. Rickettsial keratitis in a case of Mediterranean spotted fever. Eur J Ophthalmol. 1992;2:41-43.

5. Pinna A, Sechi LA, Serru A, Zanetti S, Fadda G, Carta F. Endogenous panuveitis in a patient with Rickettsia conorii infection. Acta Opthalmol Scand. 2000;78:608-609.

6. Schuil J, Richardus JH, Baarsma GS, Schaap GJ. Q fever as a possible cause of bilateral optic neuritis. Br J Ophthalmol. 1985;69:580-583.

7. Shaked Y, Samra Y. Q fever meningoencephalitis associated with bilateral abducens nerve paralysis, bilateral optic neuritis and abnormal cerebrospinal fluid findings. Infection. 1989;17:394-395.

8. Gocho K, Kondo I, Yamaki K. Identification of autoreactive T cells in Vogt-Koyanagi-Harada disease. Invest Ophthalmol Vis Sci. 2001;42: 2004-2009.

9. Morovic M, Dzelalija B, Novakovic S, Stankovic S, Dujella J. Acute renal failure as the main complication of acute infection with Coxiella burnetii. Nephron. 1993;64:335.

10. Bernstein M, Edmondson HA, Barbour BH. The liver lesion in Q fever. Clinical and pathological features. Arch Intern Med. 1965;116: 491-498.

11. Kayser K, Wiebel M, Schulze V, Gabius HJ. Necrotizing bronchitis, angiitis, and amyloidosis associated with chronic $\mathrm{Q}$ fever. Respiration. 1995;62:114-116.

12. Lumio J, Penttinen K, Pettersson T. Q fever in Finland: clinical, immunological and epidemiological findings. Scand J Infect Dis. 1981;13 $17-21$.
Clinical Ophthalmology

\section{Publish your work in this journal}

Clinical Ophthalmology is an international, peer-reviewed journal covering all subspecialties within ophthalmology. Key topics include: Optometry; Visual science; Pharmacology and drug therapy in eye diseases; Basic Sciences; Primary and Secondary eye care; Patien Safety and Quality of Care Improvements. This journal is indexed on

Submit your manuscript here: http://www.dovepress.com/clinical-ophthalmology-journal

\section{Dovepress}

PubMed Central and CAS, and is the official journal of The Society of Clinical Ophthalmology (SCO). The manuscript management system is completely online and includes a very quick and fair peer-review system, which is all easy to use. Visit http://www.dovepress.com/ testimonials.php to read real quotes from published authors. 